\title{
Assessment of Achievement Goals in Portuguese Football Referees: Exploring the Adaptation of the Task and Ego Orientation in Sport Questionnaire (TEOSQp)
}

\author{
Luis Cid $^{1,2, *}$, João Pacheco ${ }^{1}$, Carla Borrego ${ }^{1,2}$ and Carlos Silva ${ }^{1,2}$ \\ ${ }^{I}$ Sport Science School of Rio Maior (ESDRM), Portugal \\ ${ }^{2}$ Research Center for Sports Sciences, Health and Human Development (CIDESD)
}

\begin{abstract}
To measure goal perspective in sport, reflected by Achievement Goal Theory [3], Duda \& Nicholls [7] developed the Task and Ego Orientation in Sport Questionnaire (TEOSQ), that comprises 13 items to assess athletes dispositional goal orientations. However, the Portuguese version of TEOSQp, was validated in several contexts of sport: young football players [4], sport athletes, recreational exercisers and physical education students [5], and physical education students [6]. So, the main purpose of this study is to assess the factorial validity of TEOSQp and confirm the two factors model structure in a football referees population. This propose was accomplished using confirmatory factorial analysis (CFA) procedures, with data from a sample composed by 200 Portuguese football referees (155 main referees; 45 assistant referees), from different categories (69 first category; 131 third category). Adopting the criteria proposed by Hu \& Bentler [9], the results of CFA only provided support for two-factor structure and showed an reasonable model fit to the data with a 11 -items model $\left(\chi^{2}=67.42 ; \mathrm{df}=43 ; \mathrm{p}=0.01 ; \chi^{2} / \mathrm{df}=1.56 ; \mathrm{SRMR}=0.063 ; \mathrm{CFI}=0.955 ; \mathrm{RMSEA}=0.053\right.$; RMSEA 90\% IC=0.026-0.077). This model also show acceptable reliability in Cronbach's alphas for both factors (ego=.82; task=.74). These findings lead us to the elimination of item 9 and 12. However, good factor validity and reliability characteristics of the TEOSQp was obtain with the 11-items model. Nevertheless, perhaps some caution is needed in interpreting these results and more studies are advisable to a strong adaptation of TEOSQp to football referees.
\end{abstract}

Keywords: Achievement goal theory, sport psychological assessment, confirmatory factor analysis, football referees.

\section{INTRODUCTION}

According to several authors [e.g. 1, 2], Achievement Goal Theory (AGT) [3] allows a better understanding of individuals' achievement motivation in sport contexts. This approach is very important because the different conception of ability, which leads to the definition of personal success, have a significant impact on the human behavior. In other words, there are two predominant goal perspectives of success in achievement situations (i.e. Task and Ego) that can influence the individual attitude (i.e. cognitive component), guide his decision making, leads the action and determine, most of the time, the motivational levels in the activity (e.g. sport or exercise). The way that individuals pursue a particular goal orientation depends on dispositional factors (i.e. cognitions) and situational factors (i.e. motivational climate created by others). However, in the present work, we only focus on the dispositional factors because the main purpose is to assess the factorial validity of a TEOSQp (Portuguese version) and confirm the model structure in a football referees population. Until now, the Portuguese version of TEOSQp, was validated in the context of young football players [4], sport athletes, recreational exercisers and physical education students $[5,6]$.

*Address correspondence to this author at the Escola Superior de Desporto de Rio Maior, Av. Dr. Mario Soares, 2040-413 Rio Maior, Portugal; Tel: +351 243999280; Fax: +351243999292; E-mail: luiscid@esdrm.pt

\section{METHOD}

\section{Participants}

Two hundred male Portuguese football referees (155 main referees; 45 assistant referees), from different categories (69 first category; 131 third category) and 31.3 \pm 5.6 years old of mean age (between 21 and 44), participated in the study. Their experience in refereeing activity ranged from 4 to 24 years $($ Mean=11.5, $\mathrm{SD}=4.3)$.

\section{Measures}

Task and Ego Orientation in Sport Questionnaire (TEOSQ) [7]. This measure comprises 13 items to assess goal orientations reflected by the achievement of goal theory (i.e. Task and Ego orientation). Participants indicated the extent of their agreement with the subscale items on a 5point Likert-type scale ranging from 1 (strongly disagree) to 5 (strongly agree). In the present study the Portuguese version (TEOSQp) was used $[4,5]$.

\section{Procedures}

The application took place during a referee course promoted by the Portuguese Football Federation (FPF) in three different days. All participants were briefly informed about the purpose of the study and informed consent was obtained. The questionnaire application took approximately $10 \mathrm{~min}$ and was completed anonymously to encourage honest answers and to preserve confidentiality of data. 


\section{Model Testing Strategy}

The factor structure of the TEOSQp was examined through confirmatory factorial analysis (CFA) procedures using EQS 6.1 software. Model fit was assessed through the chi-square $\left(\chi^{2}\right)$ test statistic, also known as the likelihood ratio chi-square [8], and also through another popular way of evaluating model fit: the so-called fit indexes that have been offered to supplement de $\chi^{2}$ test [9].

Besides the chi-square statistic $\left(\chi^{2}\right)$ with corresponding degrees of freedom (df) and level of significance (p), several authors recommendations [e.g. 8, 10], indicated for a minimal set of fit indexes, should report the following: Standardized Root Mean Square Residual (SRMR), Comparative Fit Index (CFI), Root Mean Square Error of Approximation (RMSEA) which is $90 \%$ confidence interval (90\% CI). For the present study we adopted the cutoff criteria for fit indexes recommended by $\mathrm{Hu} \&$ Bentler [9] that included a non-significant $\chi^{2}$ test, $\quad \mathrm{CFI} \geq .95, \quad \mathrm{SRMR} \leq .08 \quad$ and RMSEA $\leq .06$.

The standard maximum likelihood (ML) estimation carries the assumption of multivariate normality in the data and in our case the distribution of the variables carries this assumption because Mardia's coefficient of multivariate kurtosis was 2.31 (normalized estimate was 0.96 ). According to Chou \& Bentler [11], the Satorra-Bentler scaled $\chi^{2}$ test (S-B $\chi^{2}$ ) should be more seriously considered only when data are not multivariate normal and that's not the case.

\section{RESULTS/DISCUSSION}

As we can see on Table 1, the two-factor model of the 13-item TEOSQp (model 1) wasn't fitted to the data with the ML method of EQS. Endorsing Hu \& Bentler [9] cutoff criteria recommendations for fit indexes, results for model 1 are generally not good and show an inadequate fit of the 13-item TEOSQp model to the data.

After analysis of modification indices suggested by $L a$ grange Multiplier test, items 9 and 12 were eliminated one at a time, with the model re-estimated at each step (model 2 and 3). This elimination can be justified by the semantic ambiguity (especially in item 9) and the observed crossloadings or extreme correlations with other items (especially in item 12). Consequently, we fit data to an alternative model without items 9 and 12 (model 4), and as can be seen (Table
1), the fit of the 11-item TEOSQp was very good and the best model was tested.

However, we can not ignore the significant $\chi^{2}$ test result. So, to reduce the sensitivity of this test to sample size (or model complexity), some researchers divide its value by the degrees of freedom [8]. This leads to the popularly normed chi-square ratio and usually a value of $\chi^{2} / \mathrm{df}$ less than 3.0 is considered a sign of a reasonable model fit [10] and values less than 2.0 and near to unit is considered a sign of a good model fit [12]. Nevertheless, a good solution was obtained with an 11-item TEOSQp (model 4).

Results also indicate a non-significant correlation $(\mathrm{r}=$ $.038, \mathrm{p} \geq .05)$ between the two factors and acceptable reliability for both factors (i.e. ego $=.82$; task=.74). Individual item factor loading ranged from .63 to $.80(\mathrm{Ego})$ and .48 to .68 (Task). Table 2 presents the 11-item means, standard deviations, standardized factor loadings (all statistically significant $p<.05$, with their standard errors), squared multiple correlations (i.e. SMC is the proportion of the variance that is explained by the predictors of the item) and measurement errors (i.e. item uniqueness) estimates.

\section{CONCLUSIONS}

Regarding the main propose of the study, a two-factor, TEOSQp (Portuguese version) only had a reasonable fit to the data (i.e. Portuguese football referees) with an 11-item model. The items 9 and 12 revealed some inconsistencies in our study that lead us to its elimination. Fernandes [6] had similar problems with item 9 in the adaptation of the TEOSQp to a physical education student's population.

Besides that, our results (i.e. 11-item model) revealed good psychometric qualities of the scale including its factorial validity (i.e. each item loads on respective factor according the original model) and internal consistency (i.e. acceptable Cronbach's alphas). For each set of items, the standardized factor loadings are all relatively high (with the exception of item 13), which suggests convergent validity. There also exists an evidence for discriminant validity because the estimated correlations between the factors are very low [8].

However, perhaps some prudence is necessary for the interpretation of these results and more studies are advisable to a strong adaptation of this scale to the Portuguese football

Table 1. Fit Indexes of the Two-Factor TEOSQp Models

\begin{tabular}{|c|c|c|c|c|c|c|c|c|}
\hline TEOSQp (Referee Population) & $\chi^{2}$ & df & $\mathbf{p}$ & $\chi^{2} / \mathbf{d f}$ & SRMR & CFI & RMSEA & $90 \%$ IC \\
\hline Model 1 13-item & 148.33 & 64 & .000 & 2.31 & .080 & .885 & .081 & $.064-.099$ \\
\hline Model 3 12-item (without item 12) & 109.69 & 53 & .000 & 2.07 & .070 & .913 & .073 & $.054-.093$ \\
\hline Model 4 11-item (without item 9, 12) & 67.42 & 43 & .010 & 1.56 & .063 & .955 & .053 & $.026-.077$ \\
\hline Model Fonseca \& Brito [5] 13-item & 810.81 & 65 & .000 & 12.47 & 0.06 & - & .91 & .94 \\
\hline TEOSQp (Physical Education Population) & $\chi^{2}$ & $\mathrm{df}$ & $\mathrm{p}$ & $\chi^{2} / \mathrm{df}$ & NNFI & $\mathrm{CFI}$ & RMSEA & GFI \\
\hline Model Fernandes [6] 13-item & 453.56 & 64 & .000 & 7.08 & .867 & .893 & .078 & .932 \\
\hline Model Fernandes [6] 12-item (without item 9) & 262.03 & 53 & .000 & 4.94 & .920 & .936 & .063 & .959 \\
\hline
\end{tabular}


Table 2. Parameter Estimates for the 11-Item TEOSQp (Referee Population)

\begin{tabular}{|c|c|c|c|c|c|c|}
\hline Items(Factor) & Mean & SD & Factor Loading & Standard Errors & Item Uniqueness & SMC \\
\hline TEOSQp1 (Ego) & 1.70 & 0.86 & .64 & .06 & .77 & .41 \\
\hline TEOSQp2 (Task) & 4.34 & 0.62 & .60 & .05 & .80 & .36 \\
\hline TEOSQp3 (Ego) & 2.51 & 1.10 & .80 & .07 & .60 & .64 \\
\hline TEOSQp4 (Ego) & 2.18 & 0.98 & .78 & .06 & .63 & .61 \\
\hline TEOSQp5 (Task) & 4.54 & 0.53 & .55 & .04 & .83 & .31 \\
\hline TEOSQp6 (Ego) & 1.69 & 0.90 & .64 & .06 & .77 & .40 \\
\hline TEOSQp7 (Task) & 4.10 & 0.71 & .52 & .06 & .85 & .27 \\
\hline TEOSQp8 (Task) & 4.16 & 0.59 & .57 & .05 & .82 & .32 \\
\hline TEOSQp10 (Task) & 4.34 & 0.53 & .68 & .04 & .73 & .46 \\
\hline TEOSQp11 (Ego) & 2.60 & 1.31 & .63 & .09 & .78 & .40 \\
\hline TEOSQp13 (Task) & 4.67 & 0.51 & .48 & .04 & .88 & .23 \\
\hline
\end{tabular}

referees. In this line of thought, the exploration of other forms of AGT assessment can not be excluded. Nevertheless, in our opinion, these findings provide initial support for the use of this scale for future research in this specific domain.

\section{REFERENCES}

[1] Roberts G. Understanding the dynamics of motivation in physical activity: the influence of achievement goals on motivational processes. In: Roberts G, Ed. Advances in motivation in sport and exercise. Champaign-Illinois: Human Kinetics 2001; pp. 1-50.

[2] Duda J. Achievement goal research in sport: Pushing the boundaries and clarifying some misunderstandings. In: Roberts G, Ed. Advances in motivation in sport and exercise. Champaign-Illinois: Human Kinetics 2001; pp. 129-82.

[3] Nicholls J. Achievement motivation. conceptions of ability, subjective experience, task choice, and performance. Psychol Rev 1984; 91(3): 328-46.

[4] Fonseca A, Biddle S. Estudo inicial para a adaptação do Task and Ego Orientation in Sport Questionnaire (TEOSQ) à realidade Portuguesa. In: Fonseca A, Ed. Estudos sobre a Motivação. Porto: Edições FCDEF-UP, 1996; pp. 65-7.
[5] Fonseca A, Brito A. A questão da adaptação transcultural de instrumentos para avaliação psicológica em contextos desportivos nacionais - o caso do Task and Ego Orientation in Sport Questionnaire (TEOSQ). Psychologica 2005; 39: 95-118

[6] Fernandes H. Análise Factorial Confirmatória do TEOSQ: Estudo Preliminar em Alunos de EF. In: Dosil J, Garcia-Prieto D, Eds. Actas do $1^{\circ}$ Congresso Galego-Português de Psicologia da Actividade Física e do Desporto. Pontevedra, 2005; pp. 8-18.

[7] Duda J, Nicholls J. Dimensions of achievement motivation in schoolwork and sport. J Educ Psychol 1992; 84: 290-9.

[8] Kline R. Principles and practice of structural equation modeling $2^{\text {nd }}$ ed. New York: The Guilford Press 2005.

[9] $\mathrm{Hu} \mathrm{L}$, Bentler P. Cutoff criteria for fit indexes in covariance structure analysis: conventional criteria versus new alternatives. Struc Equa Model 1999; 6(1): 1-55.

[10] Hair J, William B, Barry B, Rolph, A, Ronald T. Multivariate data analysis. $6^{\text {th }}$ ed. New Jersey: Pearson Educational Inc 2006.

[11] Chou C, Bentler P. Estimates and tests in structural equation modeling. In: Hoyle R, Ed. Structural equation modeling. Concepts, Issues, and Applications. California: SAGE Publications 1995; pp. 37-55.

[12] Blunch N. Introduction to Structural Equation Modeling using SPSS and AMOS. London: SAGE Publications 2008.

(c) Cid et al.; Licensee Bentham Open.

This is an open access article licensed under the terms of the Creative Commons Attribution Non-Commercial License (http://creativecommons.org/licenses/by-nc/3.0/) which permits unrestricted, non-commercial use, distribution and reproduction in any medium, provided the work is properly cited. 